\title{
Effect of Silver Nanoparticles on Fluorescence Intensity of Fluoreseina Dye Mixed in One Solution
}

\author{
Ruwaida T. Shbeeb ${ }^{1 *}$, Sarmed S. AL-Awadi ${ }^{2 a}$ and Sabreen A. Khalaf ${ }^{1 b}$ \\ ${ }^{1}$ Department of Radiology Technologies, AL-Hadi University College, Baghdad, Iraq \\ ${ }^{2}$ Department of Physics, College of Science, University of Baghdad, Baghdad, Iraq \\ aE-mail: sarmedalawadi2004@yahoo.com, bE-mail: sabreen.ali@huc.edu.iq \\ *Corresponding author: ruwaidatahsin@huc.edu.iq
}

\begin{abstract}
Metal enhanced fluorescence (MEF) is an unequaled phenomenon of metal nanoparticle surface plasmons, when light interacts with the metal nanostructures (silver nanoparticles) which result electromagnetic fields to promote the sensitivity of fluorescence. This work endeavor to study the influence of silver nanoparticles on fluorescence intensity of Fluoreseina dye by employment mixture solution with different mixing ratio. Silver nanoparticles had been manufactured by the chemical reduction method so that Ag NP layer coating had been done by hot rotation liquid method. The optical properties of the prepared samples (mixture solution of Fluoreseina dye solutions and colloidal solution with 5 minutes prepared of $\mathrm{Ag}$ NPs) tested by using UV-VIS absorption and Fluorescence spectrophotometer. by using AFM, SEM testes, the structure of silver nanoparticles had been estimated. the result of this work showed that adding Ag NPs colloidal to Fluoreseina dye solution help get a significant increase in the fluorescence intensity of this dye. this study results show that its significant to recent related studies in MEF.
\end{abstract}

Article Info.

Keywords:

Silver nanoparticle, metal-enhanced, fluorescence, chemical reduction, fluoreseina dye

\section{Article history:}

Received: Sep. 25, 2021

Accepted: Nov.14, 2021

Published: Dec. 01, 2021

\section{Introduction}

In the last decades a large number of articles have been studied the Nano metric systems. Nanostructured systems have better mechanical, chemical, and catalytic properties than bulk materials and can be utilized in different technologies. And these systems are more effective and less costly than the bulk materials [1]. due to the surface plasmon resonance absorption, noble metal nanoparticles show bright colours [2]. Silver Nanoparticles Ag NPs has high nonlinear optical properties. The Surface plasmon absorption (SPA) lies in the visible part of electromagnetic spectrum for silver particles with a size from $1-100 \mathrm{~nm}$ and it is what confers the characteristic bright yellow to $\mathrm{Ag}$ NPs colloidal solutions [3]. Ag nanoparticles can be synthesized using various methods; one of the most important and most popular preparation technique for preparing $\mathrm{Ag}$ and Au colloids is the chemical reduction method [4]. Metal enhanced fluorescence (MEF) is the interaction of the excited state of fluorophore with the localized surface plasmons of the metal nanoparticles (MNPs) and that resulted in amplifies the radiative quantum yield and increase the fluorescence intensity of the fluorophore [5]. due to Silver nanoparticle characteristic like high reflection, suitability, and biocompatibility, its common material used for MEF applications [6]. MEF has been demonstrated for many fluorophores which has nano-sized molecule [7].

The coupled system frequently demonstrates much improved photophysical qualities such as fluorophore photostability, in addition to signal amplification [8]. Organic dye molecules can absorb radiation in the ultraviolet and visible regions of the 
electromagnetic spectrum. then the dye molecules can radiatively release the absorbed energy in the form of fluorescence. Metal nanostructures are known to impact both of these processes via mechanisms such as MEF [9].

\section{Experimental work}

\subsection{Materials}

Sodium citrate and silver nitrate were received from Sigma Aldrich, dye from lambda physics, distilled water, these materials had been used without further purification.

\subsection{Preparation of silver nanoparticles solution}

$0.0425 \mathrm{gm}$ of $\mathrm{AgNO}_{3}$ in $50 \mathrm{~mL}$ deionized $\mathrm{H}_{2} \mathrm{O}$ to prepared $50 \mathrm{ml}$ as a starting solution of $\sim 5 \times 10^{-3} \mathrm{M}$ of $\mathrm{AgNO}_{3}$ in water, in order to reach $10^{-3} \mathrm{M}$ concentration, $25 \mathrm{~mL}$ of $\mathrm{AgNO}_{3}$ solution was added to $100 \mathrm{~mL}$ of $\mathrm{H}_{2} \mathrm{O}$ (now $\sim 1 \mathrm{x} 10^{-3} \mathrm{M}$ ). In another hand a solution of $1 \%$ sodium citrate $\left(0.5 \mathrm{gm}\right.$ in $50 \mathrm{~mL}$ of $\left.\mathrm{H}_{2} \mathrm{O}\right)$ has been made, then heated the $125 \mathrm{~mL}$ solution of $\mathrm{AgNO}_{3}$ until it begins to boil at $97{ }^{\circ} \mathrm{C}$. At a moment of boiling $5 \mathrm{~mL}$ of $1 \%$ sodium citrate solution has been added drop by drop, as soon as boiling commences. The colour of Colloidal solution is gradually converted with increasing the time of reduction from light yellow to dark yellow and finally becomes dark brown that's an indication to creation of silver nanoparticles with different particle size as shown in Fig.1.

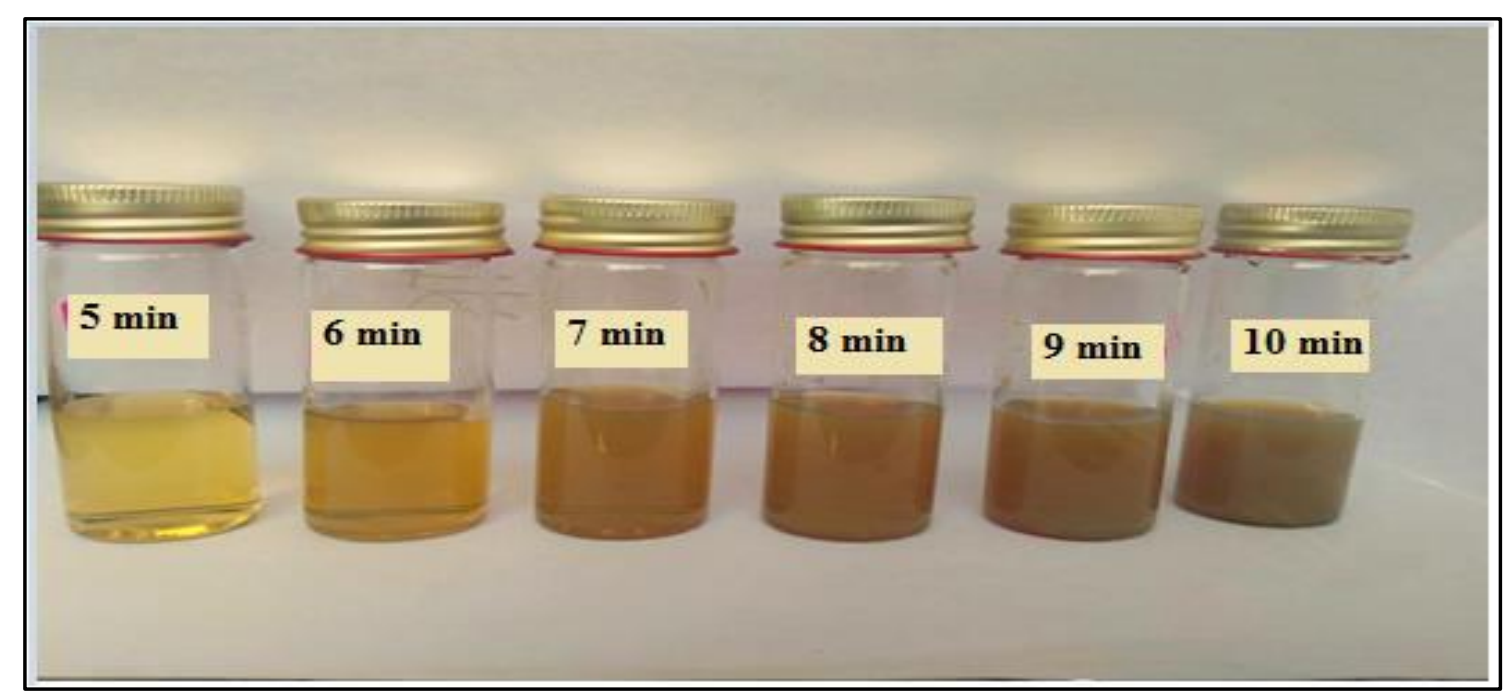

Figure 1: Prepared silver Nanoparticles by a hot chemical reduction method with different reduction periods

Silver nanoparticles had been coated onto glass microscope slide by using hot rotation liquid method [10].by dipping the microscope slide perpendicular in the hot rotation silver NP liquid for a different period's time from 5 to10 minutes as shown in Fig. 2.

\subsection{Preparation of Fluoreseina dye solutions}

The Fluoreseina dye solution is prepared by dissolving the required amount of the dye into the solvent; a Mattler balance of $0.1 \mathrm{mg}$ sensitivity is used to measure the weight of the dye. The weight of the dye (W in gm) is calculated by using the next equation [11]:

$$
W=M_{W} V C / 1000
$$

where $\mathrm{M}_{\mathrm{w}}$ is the molecular weight of the dye ( $\left.\mathrm{gm} / \mathrm{mole}\right), \mathrm{V}$ is the volume of the solvent $(\mathrm{ml}), \mathrm{C}$ is the molar concentration (mole/litre). 


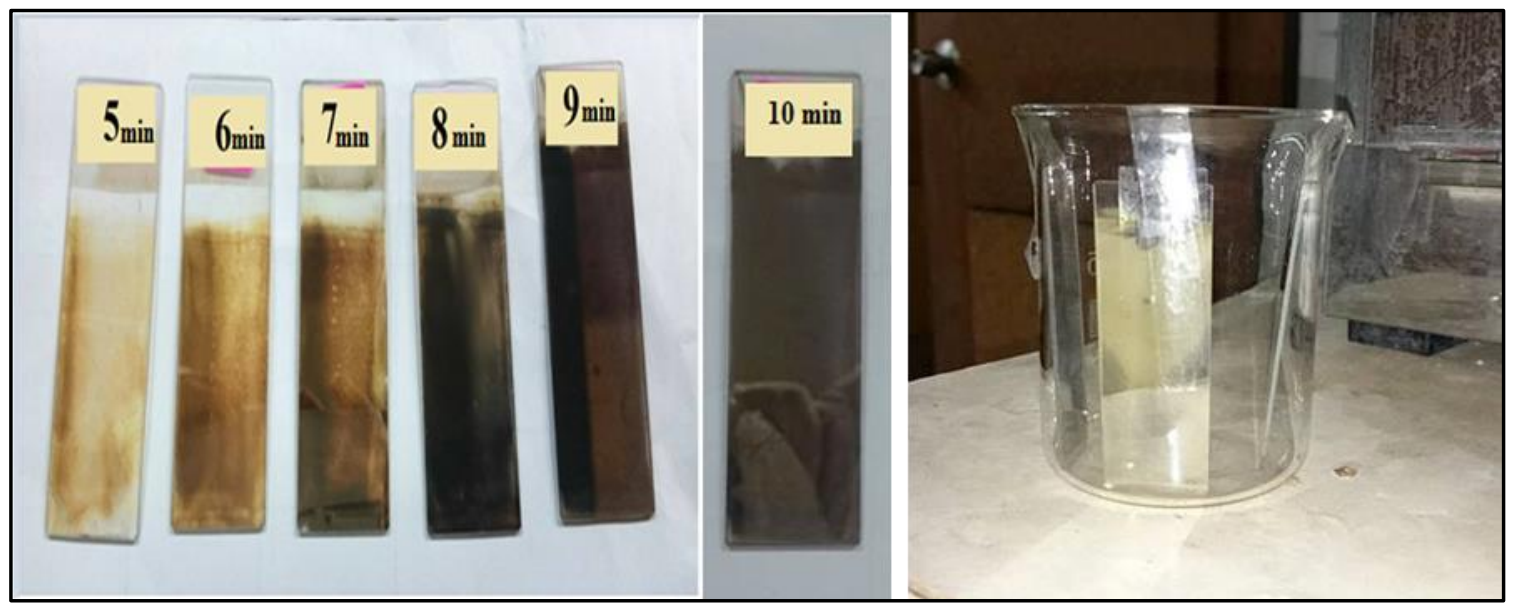

Figure 2: Ag NPs deposited on glass microscope slides by putting the slide in the hot rotation Ag NP solution at different reduction period

To prepare the diluted solutions, the next equation is used [11]:

$$
C_{1} V_{1}=C_{2} V_{2} C_{1}
$$

where $\mathrm{C}_{1}$ is the high concentration $[\mathrm{M}], \mathrm{V}_{1}$ is the volume before dilution (1), $\mathrm{C}_{2}$ is the low concentration [M], and $V_{2}$ is the total volume after dilution (1). Fluoreseina laser dye is prepared in ethanol solution with different concentrations ranging from $1 \times 10^{-2}$ to $1 \times 10^{-5}$ M.

\subsection{Mixing Ag NPs solution with dye solution}

The dye solution with concentration 10-4 $\mathrm{M}$ is mixed with silver colloid (Five minutes as a reduction period is chosen) with different mixing ratio (started from $10 \% \mathrm{Ag}$ NPs to $90 \%$ dye solution and still increase the ratio of Ag NPs colloid and decrease the ratio of dye solution until reach $50 \% \mathrm{Ag}$ NPs to $50 \%$ dye) to study the effect of adding Ag Colloidal on the optical properties of the dye.

\subsection{Structure and Optical measurements}

The optical features were investigated by UV-Vis spectroscopy for Ag NPs and Fluorescence spectroscopy for Ag and fluoreseina dye. And Total fluorescence of Ag NPs and fluoreseina dye mixture solution with different mixing ratio, the surface roughness and topography of deposited thin films were studied by AFM, additionally SEM was employed to confirm the NPs shape, size and particle size distribution.

\section{Results and discussion}

\subsection{The Atomic Force Microscope (AFM) analyses of silver nanoparticles}

The AFM is an instrument capable of measuring the topography of a given sample, Fig. 3 show the atomic force microscope results for Ag NPs which had been prepared at 5 -minute reduction periods, the particle size was $68.27 \mathrm{~nm}$. One can observe that the particle size is in the nanoparticle range.

\subsection{SEM analysis of Silver Nanoparticles}

SEM is a type of electron microscope, its powerful technique for analysing the structure of the prepared metal nanoparticles, which produces images of a sample by scanning it with a focused beam of electrons. The information about the sample's surface topography, morphology, and composition of the obtained metal nanoparticles was examined by using FE-scanning electron Microscope and shown in Fig.4. By analysis the 
results of Figure 4 one can notice that at the case of 5 minutes a particle size at the range from 22.8 to $47.6 \mathrm{~nm}$.
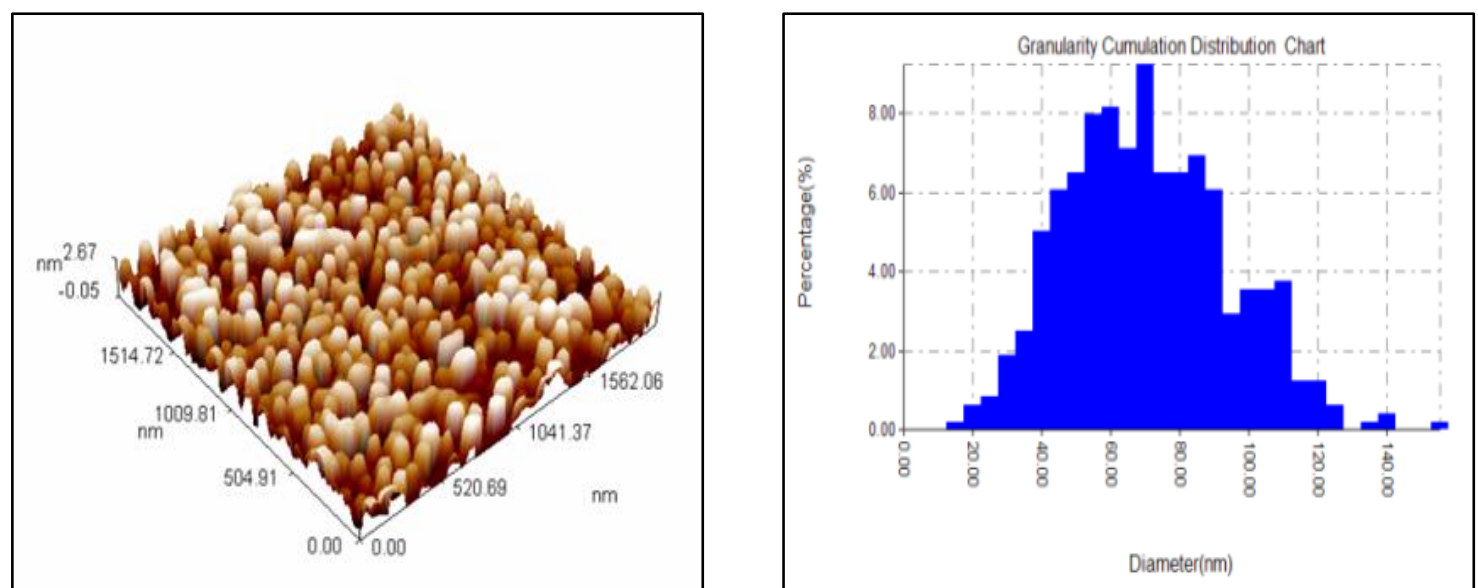

Figure 3: AFM results of prepared Ag NPs by chemical reduction method with 5 min as a reduction period

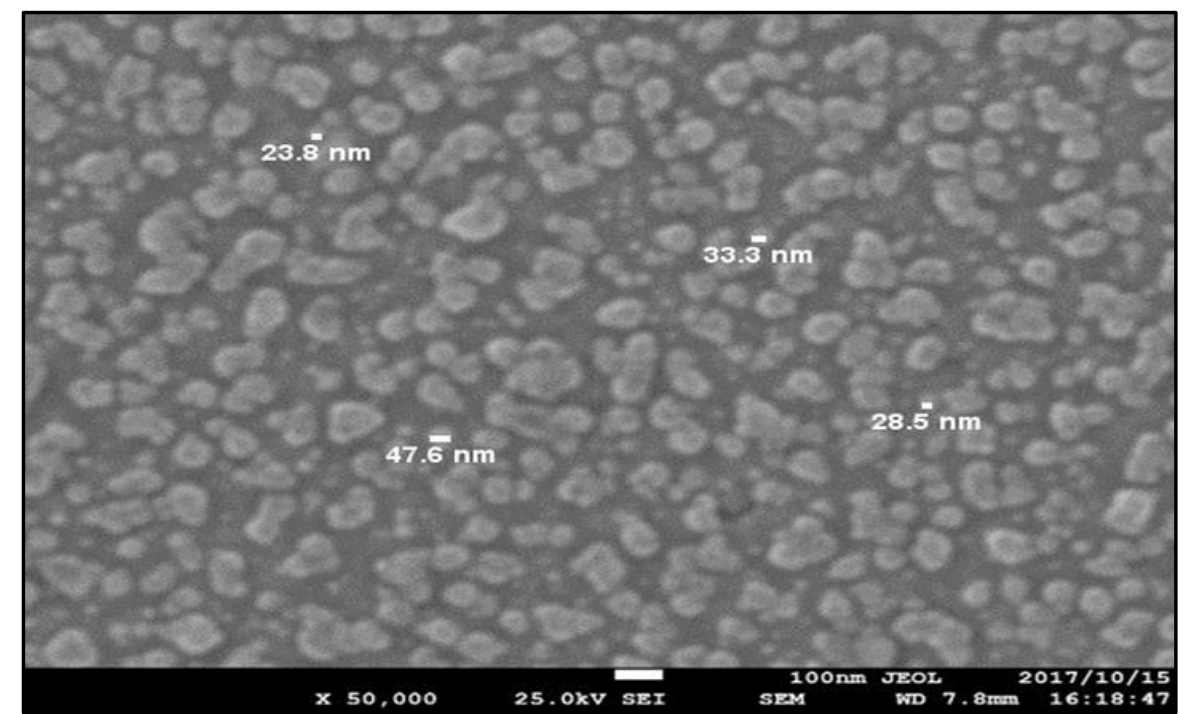

Figure 4: FE-SEM image with magnification force $=50 \mathrm{kx}$ of prepared Ag NPs by using 5 min. as a reduction period

\subsection{Absorption and Fluorescence Spectra of Ag NPs Colloidal}

\subsubsection{UV-Visible Spectrophotometer of Silver Nanoparticles}

The study of the absorption spectra introduces the first step of comprehend the agitated electronic states of molecules and gives much information related to $S^{\circ} \mathrm{Sp}$ excitation of molecules under examination. UV-Vis. spectroscopy is one of the most vastly used techniques for optical characterization of silver nanoparticles. Chemical reduction method is one of the most common and well-known methods for the preparation of silver colloids. However, the reduction period changing here, whereas the other parameters, amount of the sodium citrate aqueous solution and $\mathrm{AgNO}_{3}$ concentration are kept constant. The absorption spectrum (Fig. 5) of the light-yellow silver colloids which is prepared by hot chemical reduction method after 5 minutes from boiling point, this Figure shows the surface Plasmon absorption band with a maximum of $425 \mathrm{~nm}$ which assign to existence of $\mathrm{Ag}$ nanoparticles [10]. 


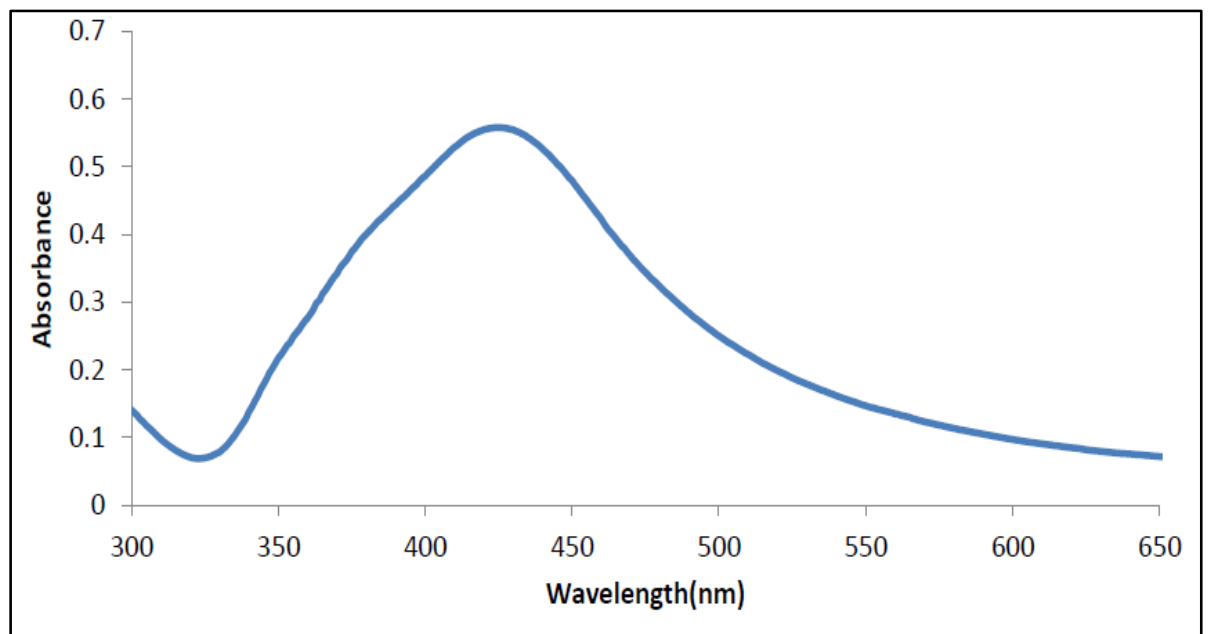

Figure 5: Absorbance spectrum of prepared Ag NPs by chemical reduction method (5 min.) as a reduction period

\subsubsection{Fluorescence Spectra of Silver Nanoparticles}

The emission spectrum of the silver colloid is examined and Fig. 6 shows that the position of the maximum fluorescence peak occurred at $494 \mathrm{~nm}$.

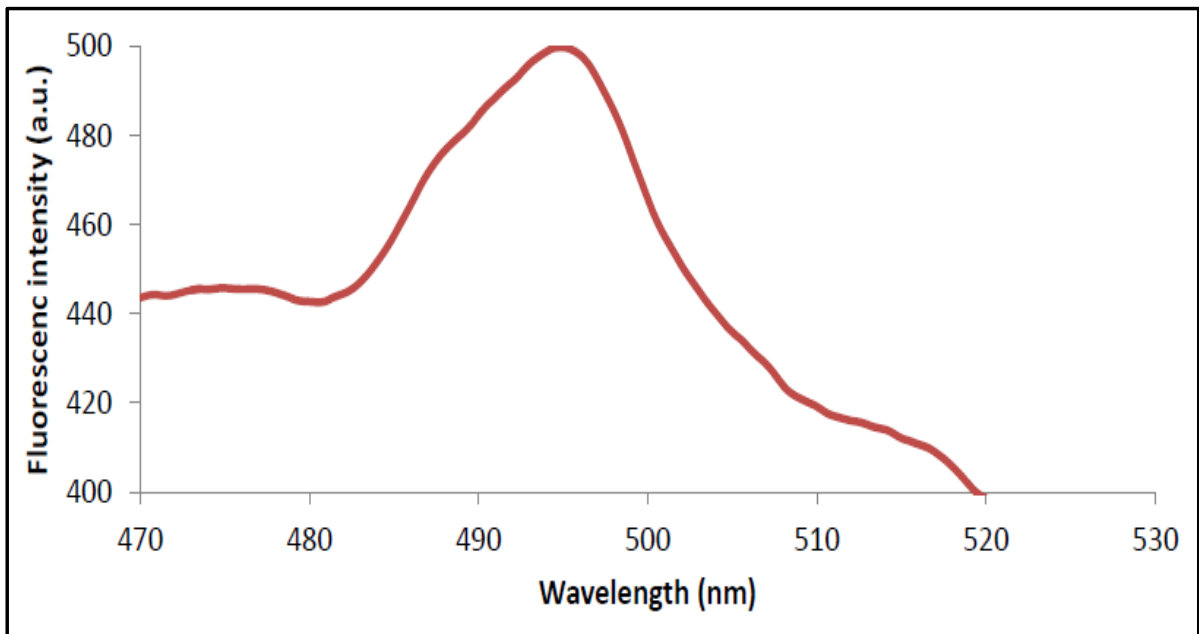

Figure 6: The Fluorescence spectrum of prepared silver nanoparticle by chemical reduction method after 5 minutes from boiling point.

\subsection{The overlap between Fluoreseina dye and Ag NPs}

The fluorescence spectrum of Fluoreseina dye which interfered with the absorption spectra for silver nanoparticles has shown in Fig.7, where the wavelength of fluorescence of Fluoreseina dye is occurred in 515.4nm and wavelength of absorption of Ag NPs colloid is occurred at $425 \mathrm{~nm}$. It can be noticed that an obvious overlap between them at $496 \mathrm{~nm}$. In Fig. 8 shows the overlap between absorption of $\mathrm{F}$ dye and fluorescence of $\mathrm{Ag}$ NPs colloid.

As shown in Fig. 9, the overlap between the absorption spectra of Ag NPs colloid and the absorption spectrum of the dye is broad and these two absorptions are overlapping at approximately the same position of spectrum. 


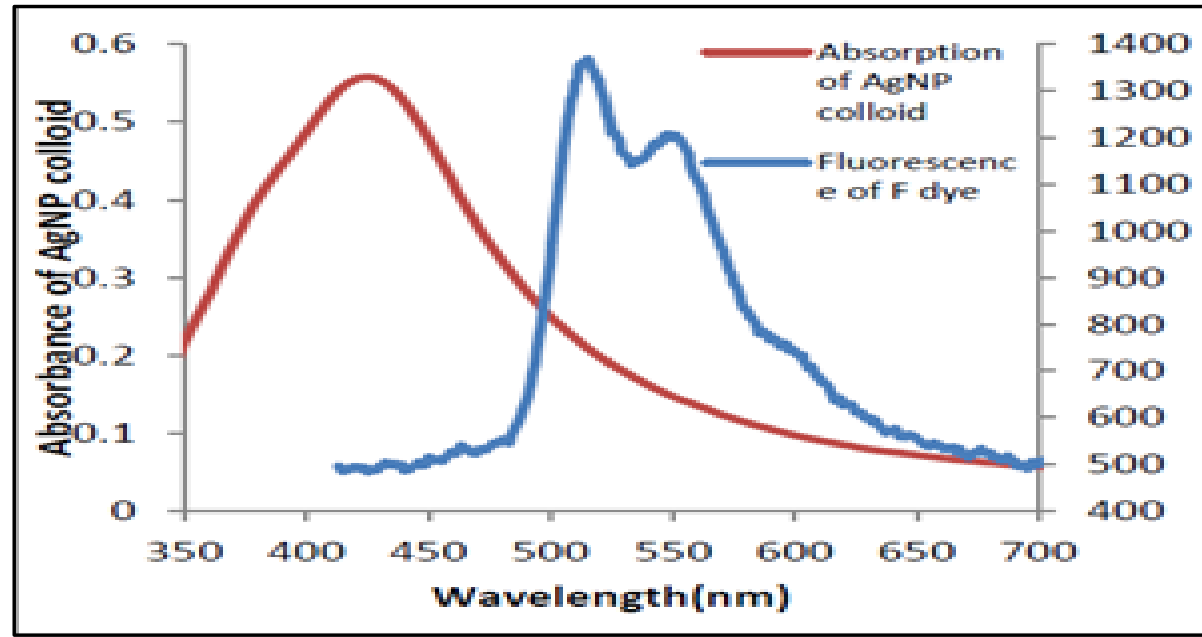

Figure 7: Overlap spectra between the surface plasmon absorption of Ag NPs (5min.) and the Fluorescence of fluoreseina dye.

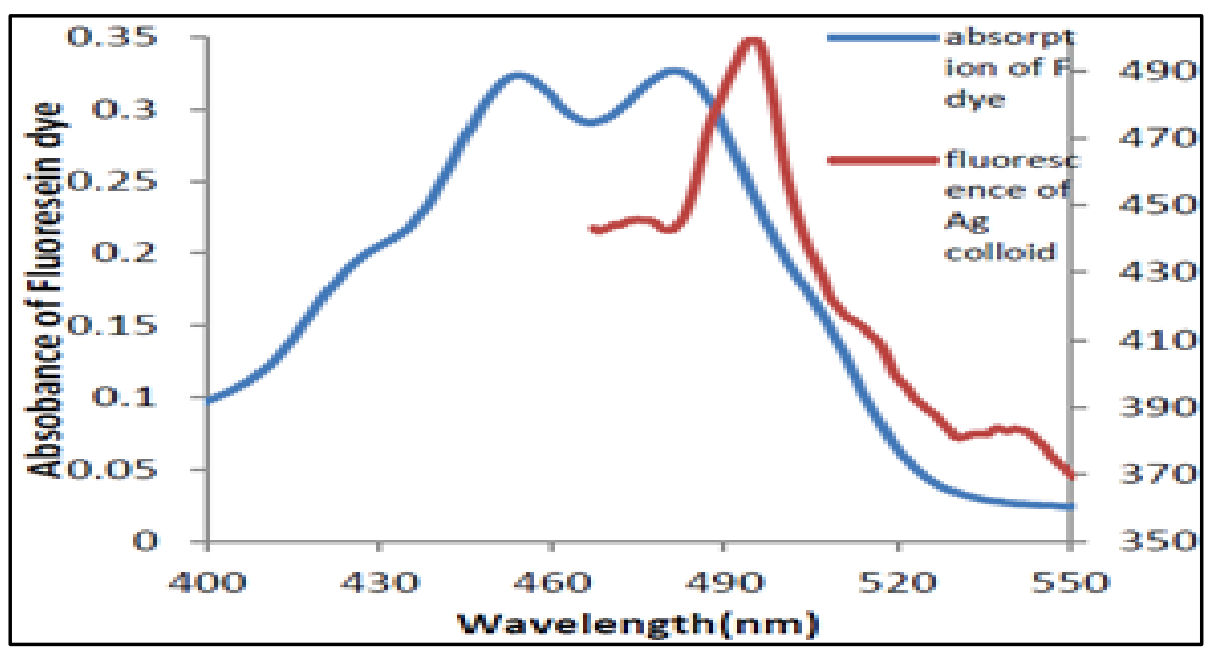

Figure 8: Overlap spectra between the absorption of fluoreseina dye and the fluorescence of Ag NPs (5 min.).

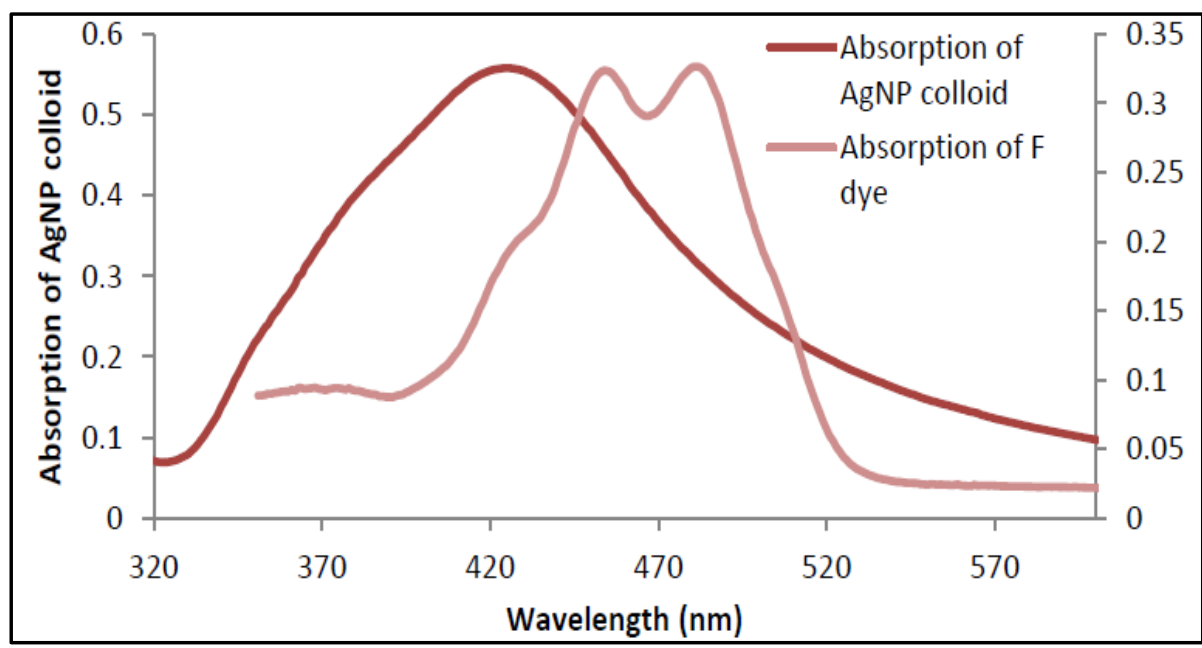

Figure 9: Overlap spectra between the surface plasmon absorption of Ag NPs (5min.) \& the Absorption of fluoreseina dye. 


\subsection{The Ag NPs and Fluoreseina dye mixing solution}

Figure 10 shows the fluorescence spectra of Ag NPs and fluoreseina dye solution mixture with different mixing ratio from (10\% to 50\%), It is obvious that the adding of Ag NPs to fluoreseina dye leads to enhance the intensity of fluorescence spectra of Fluoreseina dye, the fluorescence intensity is as high as possible at $10 \%$ mixing ratio. It can be noticed from Table 1 that the variation of the full width at half maximum (FWHM) of the emission spectrum with mixing ratio and it decreases compare to that of dye only, the variation can be reached less value at $40 \%$ mixing ratio. This decreasing in the value of FWHM is an acceptable result.

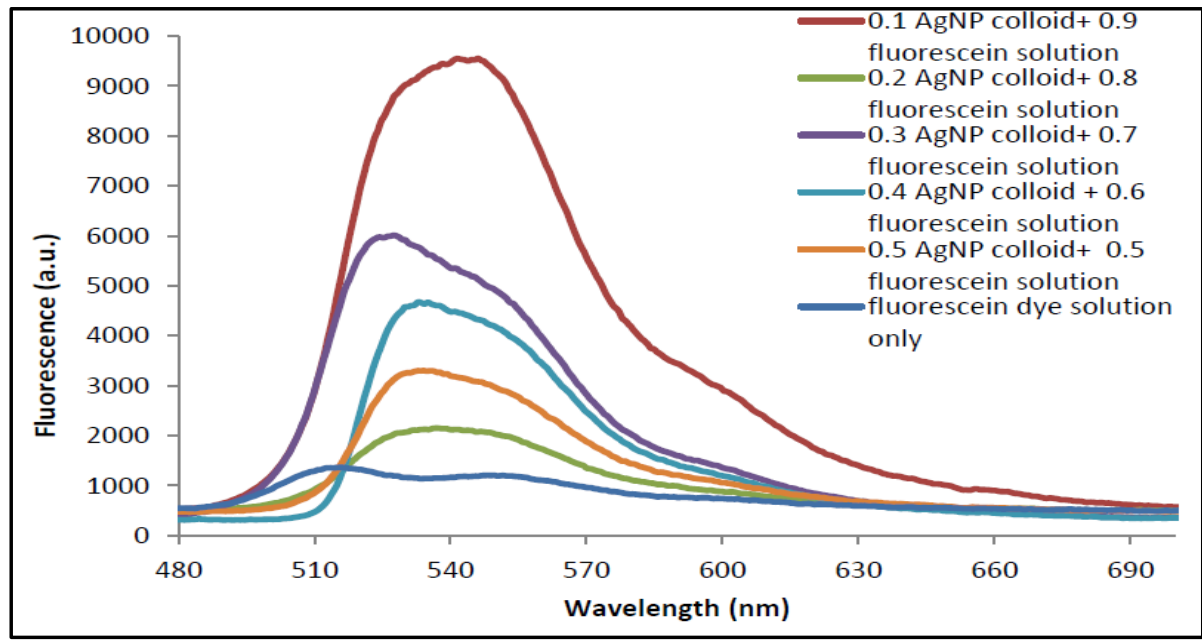

Figure 10: Total fluorescence of Ag NPs and fluoreseina dye mixture solution with different mixing ratio.

When a dye molecule is located in the vicinity of a metal surface, the energy levels of the surface Plasmon and the dye may couple, resulting in energy transfer between them. Depending on the nature of the coupling, the effect of this energy transfer may be observed as an increase in the fluorescence efficiency or dye's absorption coefficient. The dye molecule is excited by a photon or through the transfer of energy from the optically excited surface Plasmon (see Fig. 11). When the metal transfers its energy to the fluorophore, an enhancement of fluorescence is expected due to the higher absorption cross-section of the metal compared to that of the dye molecule [11]. This study results show that its great significant to recent related studies in MEF which exciting the dyes at a wavelength conforming to the Surface Plasmon resonance of nanoparticles, (as showed in these studies in references [12, 13]) study in reference [14] shows increase of fluorescence spectra of R6G-Au NPs with different molar concentration of Au NPs. One can preferentially excite the dye molecules tied to the surface of the NPs.

Table 1: The values of peak position, Maximum Fluorescence intensity and the Enhancement factor of Ag NPs and fluoreseina dye mixture with different mixing ratio.

\begin{tabular}{c|c|c|c|c}
\hline $\begin{array}{c}\text { Mixing ratio of } \\
\text { Ag NP- } \\
\text { Fluoreseina }\end{array}$ & $\begin{array}{c}\text { Peak } \\
\text { Position } \\
(\mathbf{n m})\end{array}$ & $\begin{array}{c}\text { Fluorescence } \\
\text { Intensity } \\
\text { (a.u.) }\end{array}$ & $\begin{array}{c}\text { FWHM } \\
\text { (NM) }\end{array}$ & $\begin{array}{c}\text { Enhancement } \\
\text { Factor }\end{array}$ \\
\hline $0 \%$ & 515.4 & 1369 & 117.394 & - \\
$10 \%$ & 540.9 & 9549.3 & 59.387 & 6.9 \\
$20 \%$ & 536.3 & 2154 & 69.794 & 1.5 \\
$30 \%$ & 527.4 & 6009.6 & 57.875 & 4.3 \\
$40 \%$ & 532.4 & 4677.6 & 51.784 & 3.4 \\
$50 \%$ & 533.7 & 3305.3 & 56.821 & 2.4 \\
\hline
\end{tabular}




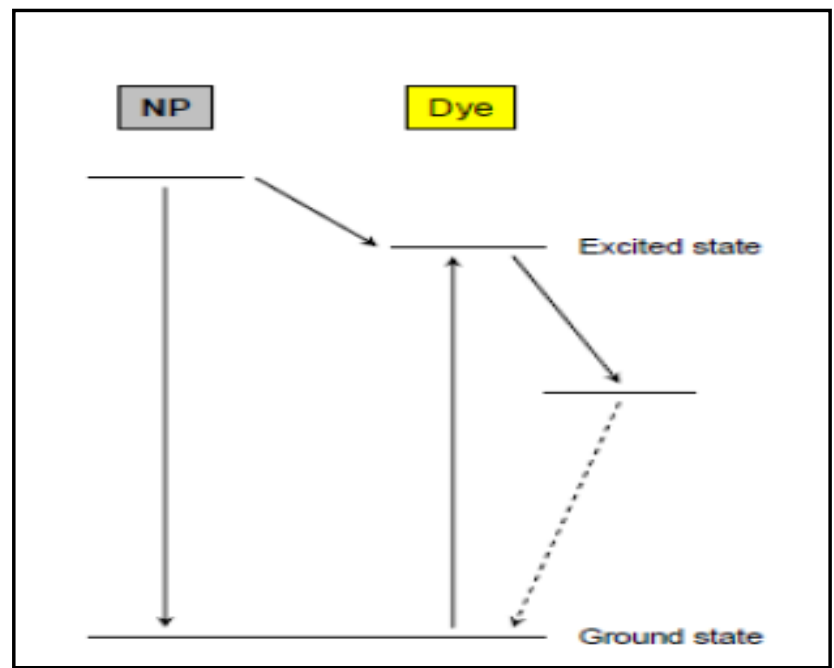

Figure 11: Energy diagrams describing surface plasmon-dye interaction, Surface enhanced fluorescence [15]

\section{Conclusions}

The optimal mixing ratio which leads to the maximum fluorescence enhancement of fluoreseina dye spectrum is $10 \%$, this ratio leads to enhance the fluorescence by factor 6.9 as shown in Table 1. While increasing the mixing ratio of Ag NPs (from 20\% to50\%) leads to decrease the fluorescence enhancement compared to $10 \% \mathrm{Ag}$ NPs, but still enhanced if it compared with dye solution only. The significant increasing in fluorescence intensity may be explained due to the large overlap between the absorption spectrum of Ag NPs and the absorption spectrum of fluoreseina dye, which makes the Fluoreseina dye affects positive by the Ag NPs, so it starts to irritate more. Fig. 10 shows that the peak of the fluorescence signal moves to longer wavelengths. The largest shift is appeared at $10 \%$ of Ag NPs and reached to $540.9 \mathrm{~nm}$. This MEF arises from the coupling of fluorophore of the dye to silver nanoparticle surface plasmons such that the coupled system may radiate as a single system. In future works we will try to study a biological or medical application by using the Ag NPs-fluoreseina dye which exhibit remarkable optical properties that make them suitable for biosensing and imaging applications. In particular, Ag NPsfluoreseina dye is a promising material for biotechnological applications.

\section{Acknowledgments}

The authors would like to thanks Department of Physics/College of Science/ in the University of Baghdad for supporting the work in the labs.

\section{Conflict of interest}

Authors declare that they have no conflict of interest.

\section{References}

1. Gama-Lara S.A., Perez Mendoza M.S., Vilchis-Nestor A.R., and Natividad R., Bionanotechnology: silver nanoparticles supported on bovine bone powder used as bactericide. Materials, 2020. 13(2): pp. 462.

2. Eustis S., Gold and silver nanoparticles: characterization of their interesting optical properties and the mechanism of their photochemical formation, Thesis, Georgia Institute of technology, 2006.

3. Amendola V., Synthesis of gold and silver nanoparticles for photonic applications. Thesis, 2008. 
4. Ratyakshi and Chauhan R., Colloidal synthesis of silver nano particles. Asian Journal of Chemistry, 2009. 21(10): pp. 113-116.

5. Iqbal S., Shabaninezhad M., Hatshan M., Niraula P.M., Abuhagr A., Alali H., Guda R., and Kayani A., Ion-implanted silver nanoparticles for metal-enhanced fluorescence. AIP Advances, 2018. 8(9): pp. 095217.

6. Badshah M.A., Koh N.Y., Zia A.W., Abbas N., Zahra Z., and Saleem M.W., Recent developments in plasmonic nanostructures for metal enhanced fluorescence-based biosensing. Nanomaterials, 2020. 10(9): pp. 1749.

7. Knoblauch R., Ra E., and Geddes C.D., Heavy carbon nanodots 2: plasmon amplification in Quanta Plate ${ }^{\mathrm{TM}}$ wells and the correlation with the synchronous scattering spectrum. Physical Chemistry Chemical Physics, 2019. 21(3): pp. 12541259.

8. Lucas E., Knoblauch R., Combs-Bosse M., Broedel Jr S.E., and Geddes C.D., Lowconcentration trypsin detection from a metal-enhanced fluorescence (MEF) platform: Towards the development of ultra-sensitive and rapid detection of proteolytic enzymes. Spectrochimica Acta Part A: Molecular Biomolecular Spectroscopy, 2020. 228: pp. 117739.

9. Dogantzis N.P., Hodgson G.K., and Impellizzeri S., Optical writing and single molecule reading of photoactivatable and silver nanoparticle-enhanced fluorescence. Nanoscale Advances, 2020. 2(5): pp. 1956-1966.

10. Derom S., Berthelot A., Pillonnet A., Benamara O., Jurdyc A.-M., Girard C., and des Francs G.C., Metal enhanced fluorescence in rare earth doped plasmonic core-shell nanoparticles. Nanotechnology, 2013. 24(49): pp. 495704.

11. Zhang J. and Lakowicz J.R., Metal-enhanced fluorescence of an organic fluorophore using gold particles. Optics express, 2007. 15(5): pp. 2598-2606.

12. Fratoddi I., Battocchio C., Iucci G., Catone D., Cartoni A., Paladini A., O'Keeffe P., Nappini S., Cerra S., and Venditti I., Silver Nanoparticles Functionalized by Fluorescein Isothiocyanate or Rhodamine B Isothiocyanate: Fluorescent and Plasmonic Materials. Applied Sciences, 2021. 11(6): pp. 2472.

13. Al-Arab H.S., Al-Kadhemy M.F.H., and SAEED A.A.A., Estimation of Theoretical Models of Photophysical Processes for Fluorescein Laser Dye with Ag Nanoparticles. Gazi University Journal of Science, 2021. 34(2): pp. 550-560.

14. Matveeva K., Zyubin A., Ognedyuk A., Demishkevich E., Kon I., and Samusev I., Photophysical Properties of Au and Au@Sio2 Nanoparticle-Dye Complexes in Mesoporous Silica Matrices for Theranostics Purposes. Romanian Journal of Physics, 2021. 66(7-8).

15. Ray K., Badugu R., and Lakowicz J.R., Distance-dependent metal-enhanced fluorescence from Langmuir- Blodgett monolayers of alkyl-NBD derivatives on silver island films. Langmuir, 2006. 22(20): pp. 8374-8378. 
تأثير جسيمات الفضة النانوية على شدة الفلورة لصبغة الفلورسينا عند خلطهم بمحلول واحد

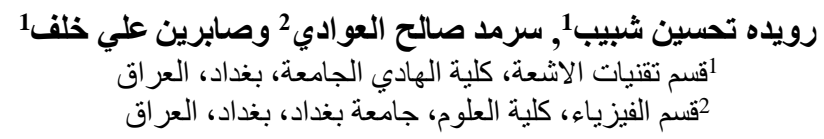

الخلاصة

الفلورة المعززة بالمعادن هي ظاهرة فريدة من نوعها نتيجة وجود بلازمونات الفات سطحية للجسيمات المعدنية

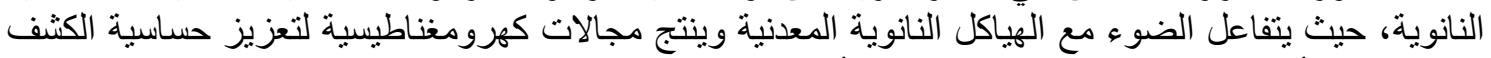

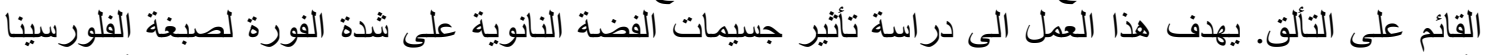

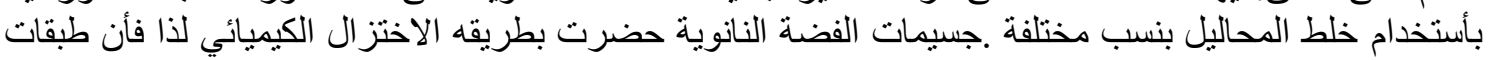

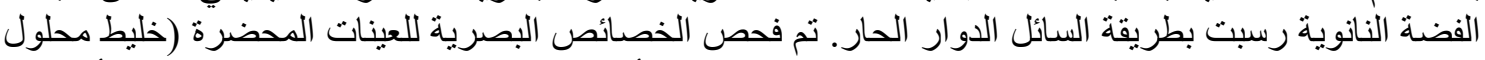

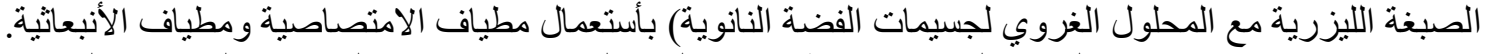

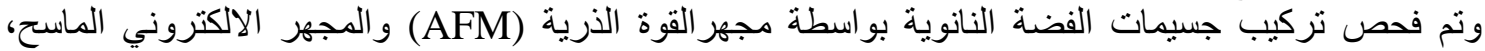

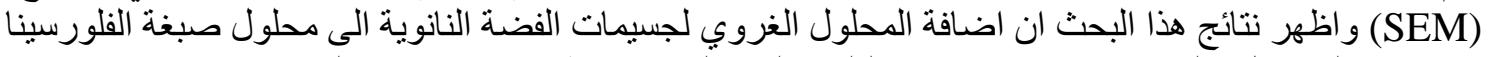

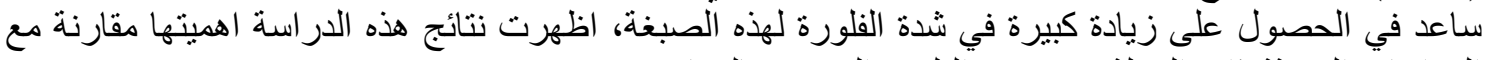
الدر اسات الحديثة ذات الصلة بموضول كيرة في الفلورة المعززة بالمعادة. 